\title{
Kandungan Giberelin, Kinetin, dan Asam Absisat pada Tanaman Durian yang Diberi Paklobutrazol dan Etepon
}

\author{
Content of Gibberellin, Kinetin, and Abscisic acid on Durian Plant Treated Paclobutrazol and \\ Ethephon
}

\author{
Sakhidin $^{1} *$ dan Slamet Rohadi Suparto ${ }^{1}$
}

Diterima 9 Desember 2010/Disetujui 2 Maret 2011

\begin{abstract}
Application of paclobutrazol and ethephon is a method to induce flowering of durian. Mecanism of flowering induction was related with the content of some endogenous hormones. The objective of this research was to study content of gibberellin, kinetin, and abscisic acid on durian plant treated by paclobutrazol and ethephon. The treatments were paclobutrazol dosages (a.i. g per tree): 0,2, and 4; and ethephon concentration (ppm) : 0, 400, and 800; it were replicated 3 times. The material of this research was durian plant var Monthong 10 years age. The result showed that interaction between paclobutrazol dosages and ethephon concentration affected significantly the number of flower and content of gibberellin and abscisic acid. Plant durian treated by 4 $g$ paclobutrazol and 800 ppm ethephon has the lowest content of gibberellin and abscisic acid but the highest number of flower. Application of $4 \mathrm{~g}$ paclobutrazol showed the lowest content of gibberellin but the highest content of kinetin. The same result was showed by 800 ppm ethephon.
\end{abstract}

Key words : durian, paclobutrazol, ethephon, edogenous hormones

\section{PENDAHULUAN}

Durian merupakan salah satu jenis buah tropik yang banyak disukai dan mempunyai nilai ekonomis tinggi, sehingga prospektif untuk dikembangkan secara komersial. Namun demikian panen buah ini bersifat musiman, sehingga menimbulkan fluktuasi ketersediaan buah dan harga. Pada saat musim panen, buah durian melimpah sehingga harga relatif murah, sedangkan pada saat tidak musim panen terjadi kondisi sebaliknya.

Manipulasi lingkungan tanaman agar pohon durian dapat berbuah di luar musim merupakan upaya perentangan periode pembuahan dengan mempercepat awal musim buah atau memperlambat akhir musim buah. Hal ini akan memperbaiki pasokan dan harga buah durian. Poerwanto (2003) menyatakan bahwa dengan cara ini tidak semua pohon berbuah pada saat yang bersamaan, sehingga keseimbangan penawaran dan permintaan dalam rentang waktu yang panjang dapat diperbaiki. Untuk itu perlu dikembangkan teknologi produksi buah di luar musim.

Faktor lingkungan yang seringkali dapat menginduksi pembungaan tanaman buah di daerah tropis terutama berupa stres air. Namun demikian stres air bagi tanaman yang dapat diperoleh secara alami seringkali mengalami tidak tepat waktu. Untuk itu perlu dikembangkan manipulasi stres air atau menciptakan kondisi stres air bagi tanaman secara buatan. Salah satu cara manipulasi tersebut adalah pembuatan saluran drainase atau parit yang dalam di sekitar pangkal batang.

Manipulasi stres air pada tanaman untuk induksi pembungaan seringkali memerlukan perlakuan tambahan agar induksi bunga tersebut dapat dipercepat dan serempak. Salah satu perlakuan tersebut adalah pemberian paklobutrazol dan etepon. Namun demikian pengaruhnya sangat ditentukan dosis dan konsentrasi yang diberikan. Dengan demikian perlu dilakukan penelitian dengan tujuan untuk mengetahui pengaruh dosis paklobutrazol dan konsentrasi etepon terhadap pembungaan durian, baik masing-masing pengaruh tunggalnya maupun interaksinya.

\section{BAHAN DAN METODE}

Penelitian dilakukan di kebun durian di Desa Kecila, Kecamatan Kemranjen, Kabupaten Banyumas, Jawa Tengah. Penelitian berlangsung dari bulan April sampai dengan Nopember 2009. Materi penelitian yang digunakan adalah tanaman durian kultivar Monthong yang telah berumur 10 tahun. Bahan penelitian meliputi paklobutrazol, etepon, pupuk kandang, pupuk NPK, pestisida, bahan kimia untuk analisis giberelin, kinetin, dan

${ }^{1}$ Staf Pengajar Fakultas Pertanian Unsoed, Purwokerto

Fakultas Pertanian Unsoed Kampus Karangwangkal, Purwokerto 53123. Telp./Fax. : (0281) 638791

Email : sakhidin 1207@yahoo.com, HP. : 08128390939

(*Penulis untuk korespondensi) 
asam absisat. Alat yang digunakan antara lain kotak pendingin, pengering beku (freeze dryer), dan HPLC.

Penelitian ini merupakan percobaan faktorial dari dua faktor dengan menggunakan Rancangan Acak Kelompok (RAK). Faktor yang pertama adalah dosis paklobutrazol ( $\mathrm{g}$ b.a per pohon) : 0,2 , dan 4; sedangkan faktor ke dua adalah konsentrasi etepon (ppm): 0, 400, dan 800 .

Variabel yang diamati meliputi saat pertama berbunga, jumlah bunga, jumlah buah terbentuk, fruit-set dan kandungan fitohormon (giberelin, kinetin dan asam absisat). Contoh daun segar (yang sudang matang secara fisiologis, sekitar $10 \mathrm{~g}$ ) diambil dari pohon lalu segera dimasukkan ke dalam kotak pendingin yang berisi es kering. Contoh daun difreeze dryer, lalu disimpan dalam lemari pembeku pada suhu $-18{ }^{\circ} \mathrm{C}$. Untuk keperluan analisis selanjutnya, contoh daun yang sudah kering ditumbuk halus. Prosedur analisis sitokinin dan giberelin mengikuti Metode Linskensen dan Jackson (1987). Contoh daun $0.2 \mathrm{~g}$ diekstrak dengan $\mathrm{MeOH}$ $80 \%$ pada $5^{\circ} \mathrm{C}$ selama 48 jam, lalu disaring. Filtrat diuapkan dalam vacuum pada $35{ }^{\circ} \mathrm{C}$ sampai tingkat fase air, lalu diencerkan dengan ILO sampai $50 \mathrm{ml}$, $\mathrm{pH}$ diatur 2.5-3, ditambahkan PVP dan disaring, dan diekstraksi dengan etil asetat $10 \mathrm{ml}$. Fase air diambil untuk analisis sitokinin, melalui beberapa tahapan berikutnya akan diperoleh eluat. Eluat tersebut diinjeksikan ke HPLC dengan fase diam C18, fase cair methanol asam asetat, dan detektor $\lambda 210 \mathrm{~nm}$. Fraksi etil asetatnya digunakan untuk analisis giberelin, setelah melalui beberapa tahapan berikunya akan diperoleh eluat. Eluat diinjeksikan ke HPLC dengan fase diam C18, fase cair methanol asam asetat, detektor dengan $\lambda 225 \mathrm{~nm}$. Ekstraksi untuk analisis asam absisat ( Modifikasi Neil dan Horgan, 1987 dalam Murniati 1995) diawali dengan menambahkan $10 \mathrm{ml}$ methanol $80 \%$ pada $0.2 \mathrm{~g}$ contoh daun, diencerkan pada $4{ }^{\circ} \mathrm{C}$, disaring, $\mathrm{pH}$ diatur 8-10. Pemurnian dilakukan dengan menggunakan resin penukar kation anion Dowex 20, disaring dengan milipore organik. Eluat yang dihasilkan diinjeksikan ke HPLC dengan fase diam $\mathrm{C} 18$, fase cair methanol asam asetat, dan detektor $\lambda$ $265 \mathrm{~nm}$. Konsentrasi endogenous hormones ditentukan dengan menganalisis perbandingan antara luas area contoh dan luas area standar dikalikan konsentrasi standar. Data hasil pengamatan dianalisis dengan Uji $\mathrm{F}$, apabila hasilnya nyata maka dilanjutkan uji DMRT taraf 5\%.

\section{HASIL DAN PEMBAHASAN}

Ringkasan hasil analisis statistik data hasil pengamatan disajikan pada Tabel 1 . Tabel tersebut menunjukkan bahwa interaksi antara dosis paklobutrazol dan konsentrasi etepon berpengaruh sangat nyata terhadap konsentrasi giberelin, asam absisat dan berpengaruh nyata terhadap jumlah bunga. Dosis paklobutrazol berpengaruh sangat nyata terhadap hampir semua variabel yang diamati kecuali asam absisat. Konsentrasi etepon berpengaruh sangat nyata terhadap jumlah bunga, jumlah buah, fruit-set, kandungan giberelin, dan kinetin.

Tabel 1. Matriks hasil analisis statistik data pengaruh dosis paklobutrazol dan konsentrasi etepon terhadap pembungaan durian

\begin{tabular}{clccc}
\hline No. & $\begin{array}{l}\text { Variabel } \\
\text { yang } \\
\text { Diamati }\end{array}$ & $\begin{array}{c}\text { Dosis } \\
\text { paklo- } \\
\text { butrazol }\end{array}$ & $\begin{array}{c}\text { Konsentrasi } \\
\text { etepon }\end{array}$ & $\begin{array}{c}\text { Inter } \\
\text { aksi }\end{array}$ \\
\hline 1 & $\begin{array}{l}\text { Saat } \\
\text { pertama } \\
\text { berbunga }\end{array}$ & $* *$ & tn & tn \\
2 & $\begin{array}{l}\text { Jumlah } \\
\text { bunga }\end{array}$ & $* *$ & $* *$ & $*$ \\
3 & $\begin{array}{l}\text { Jumlah } \\
\text { buah }\end{array}$ & $* *$ & $* *$ & tn \\
4 & $\begin{array}{l}\text { Fruit-set } \\
5\end{array}$ & $* *$ & $* *$ & $* *$ \\
6 & $\begin{array}{l}\text { Giberelin } \\
\text { Kinetin }\end{array}$ & $* *$ & $* *$ & tn \\
7 & $\begin{array}{l}\text { Asam } \\
\text { absisat }\end{array}$ & tn & $* *$ & tn \\
\hline Keterangan : tn $=$ tidak nyata, $*$ nyata pada \\
taraf $95 \%, * *=$ nyata pada taraf
\end{tabular}

\section{Pengaruh Interaksi antara Dosis Paklobutrazol dan Konsentrasi Etepon}

Pengaruh interaksi antara dosis paklobutrazol dan konsentrasi etepon terhadap jumlah bunga, kandungan giberelin, dan asam absisat disajikan masing-masing pada Gambar 1, Gambar 2, dan Gambar 3. Gambar 1 menunjukkan bahwa pengaruh dosis paklobutrazol terhadap jumlah bunga dipengruhi oleh konsentrasi etepon. Pada 0 ppm etepon, peningkatan dosis paklobutrazol dari 0 sampai dengan $4 \mathrm{~g}$ bahan aktif per pohon tidak nyata meningkatkan jumlah bunga; sedangkan pada 400 dan 800 ppm etepon, peningkatan dosis paklobutrazol secara nyata meningkatkan jumlah bunga. 
Peningkatan dosis paklobutrazol menurunkan konsentrasi giberelin, namun penurunan giberelin terlihat lebih tajam pada 400 ppm etepon dibandingkan dengan 0 dan $800 \mathrm{ppm}$ etepon (Gambar 2). Gambar 3 menunjukkan bahwa pada $400 \mathrm{ppm}$ etepon, peningkatan dosis paklobutrazol meningkatkan kandungan asam absisat. Namun pada 0 dan 800 ppm etepon, peningkatan dosis paklobutrazol menurunkan kandungan asam absisat.

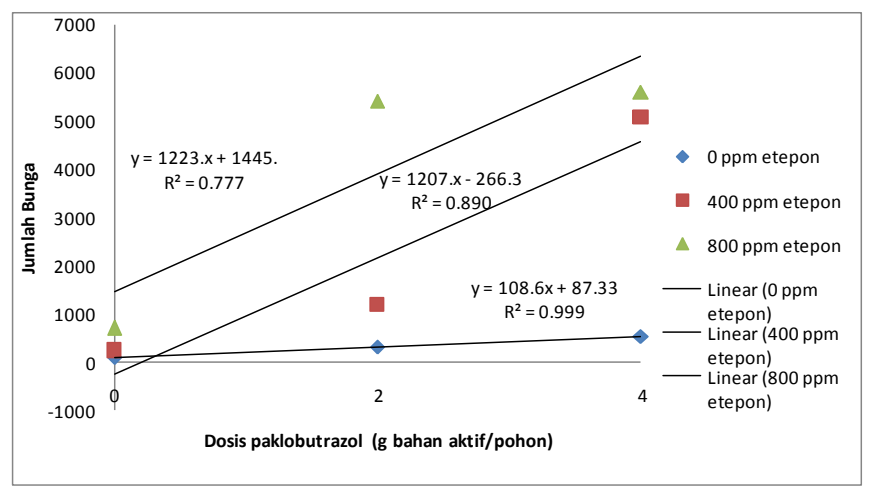

Gambar 1. Pengaruh interaksi antara dosis paklobutrazol dan konsentrasi etepon terhadap jumlah bunga

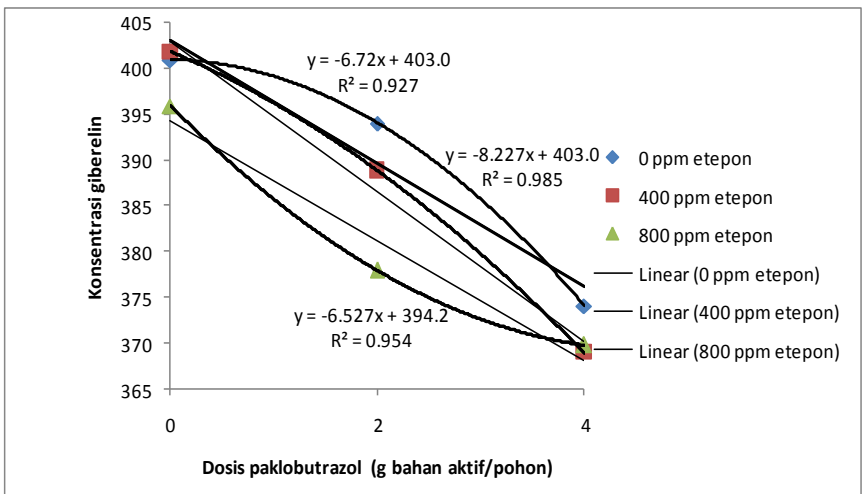

Gambar 2. Pengaruh interaksi antara dosis paklobutrazol dan konsentrasi etapon terhadap konsentrasi giberelin

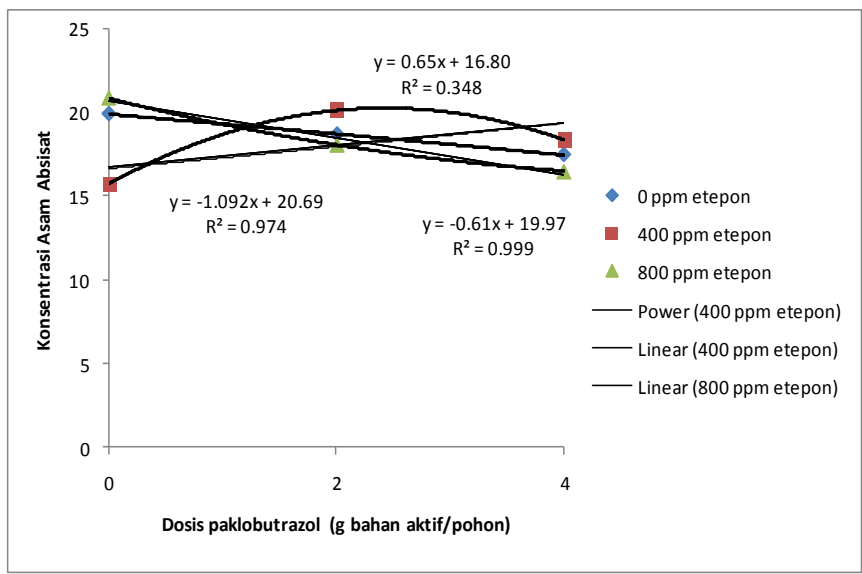

Gambar 3. Pengaruh interaksi anatara dosis paklobutrazol dan konsentrasi etapon terhadap konsentrasi asam absisat 


\section{Pengaruh Dosis Paklobutrazol}

Tabel 2 menunjukkan bahwa pemberian paklobutrazol $4 \mathrm{~g}$ bahan aktif per pohon mempercepat pembungaan durian dibandingkan dengan pohon durian yang tidak diberi paklobutrazol. Pemberian paklobutrazol pada dosis tersebut juga meningkatkan jumlah bunga, jumlah buah, namun menurunkan fruit-set, lebih cepat munculnya bunga durian dan tingginya jumlah bunga, jumlah buah, namun fruit-set yang rendah melalui pemberian $4 \mathrm{~g}$ bahan aktif paklobutrazol per pohon berkaitan dengan rendahnya kandungan giberelin dan tingginya kinetin. Hasil penelitian ini sesuai dengan pernyataan Baktir et al (2004), kandungan giberelin yang lebih tinggi pada tanaman akan menginduksi pembentukan kuncup vegetatif sedangkan kandungan yang lebih rendah akan menginduksi kuncup bunga. Giberelin sangat menghambat pembungaan walaupun mekanismenya belum sepenuhnya dipahami (Palesa dan Crocker, 2002). Rendahnya fruit-set berkaitan dengan tidak sempurnanya perkembangan bunga (Naoko et al., 2005) dan gugurnya bunga selama proses berlangsungnya penyerbukan dan pembuahan (Palupi et al., 2010).

\section{Pengaruh Konsentrasi Etepon}

Tabel 3 menunjukkan bahwa pemberian etepon 800 ppm secara nyata meningkatkan jumlah bunga, jumlah buah dan fruit-set. Jumlah bunga dan jumlah buah tertinggi yang dicapai melalui pemberian 800 ppm etepon terkait dengan menurunnya kandungan giberelin dan meningkatnya kinetin. Pada konsentrasi etepon tersebut menunjukkan fruit-set terendah walaupun tidak berbeda nyata dengan fruit-set yang dicapai melalui 400 ppm etepon. Pemberian $800 \mathrm{ppm}$ etepon menghasilkan bunga lebih dari 10 kali dan buah hampir 4 kali dibandingkan 0 ppm etepon, namun fruit-set kurang dari sepertiganya.

Tabel 2. Pengaruh dosis paklobutrazol terhadap saat pertama berbunga, jumlah bunga, jumlah buah, fruitset, kandungan giberelin, kinetin, dan asam absisat.

\begin{tabular}{cccccccc}
\hline $\begin{array}{c}\text { Dosis paklobutrazol } \\
\text { (g bahan aktif/pohon }\end{array}$ & $\begin{array}{c}\text { Saat } \\
\text { pertama } \\
\text { berbunga } \\
\text { (HSAE) }\end{array}$ & $\begin{array}{c}\text { Jumlah } \\
\text { bunga }\end{array}$ & $\begin{array}{c}\text { Jumlah } \\
\text { buah }\end{array}$ & $\begin{array}{c}\text { Fruit-set } \\
(\%)\end{array}$ & $\begin{array}{c}\text { Giberelin } \\
(\mathrm{ppm})\end{array}$ & $\begin{array}{c}\text { Kinetin } \\
(\mathrm{ppm})\end{array}$ & $\begin{array}{c}\text { Asam } \\
\text { absisat } \\
(\mathrm{ppm})\end{array}$ \\
\hline 0 & $19.11 \mathrm{~b}$ & $334 \mathrm{c}$ & $49.11 \mathrm{~b}$ & $14.74 \mathrm{a}$ & $399.56 \mathrm{a}$ & $22.07 \mathrm{c}$ & $18.88 \mathrm{a}$ \\
2 & $13.56 \mathrm{a}$ & $2,292 \mathrm{~b}$ & $52.67 \mathrm{~b}$ & $2.32 \mathrm{~b}$ & $386.93 \mathrm{~b}$ & $25.28 \mathrm{~b}$ & $19.01 \mathrm{a}$ \\
4 & $12.22 \mathrm{a}$ & $3,720 \mathrm{a}$ & $76.22 \mathrm{a}$ & $2.06 \mathrm{~b}$ & $370.93 \mathrm{c}$ & $28.13 \mathrm{a}$ & $17.48 \mathrm{a}$ \\
\hline
\end{tabular}

Keterangan : Angka yang diikuti oleh huruf yang berbeda pada kolom yang sama adalah berbeda nyata pada uji DMRT taraf 5\%. HSAE = hari setelah aplikasi etepon

Tabel 3. Pengaruh konsentrasi etepon terhadap saat pertama berbunga, jumlah bunga, jumlah buah, fruitset, kandungan giberelin, kinetin, dan asam absisat.

\begin{tabular}{cccccccc}
\hline $\begin{array}{c}\text { Konsentrasi } \\
\text { etepon } \\
(\mathrm{ppm})\end{array}$ & $\begin{array}{c}\text { Saat pertama } \\
\text { berbunga } \\
\text { (HSAE) }\end{array}$ & $\begin{array}{c}\text { Jumlah } \\
\text { bunga }\end{array}$ & $\begin{array}{c}\text { Jumlah } \\
\text { buah }\end{array}$ & $\begin{array}{c}\text { Fruit-set } \\
(\%)\end{array}$ & $\begin{array}{c}\text { Giberelin } \\
(\mathrm{ppm})\end{array}$ & $\begin{array}{c}\text { Kinetin } \\
(\mathrm{ppm})\end{array}$ & $\begin{array}{c}\text { Asam } \\
\text { absisat } \\
(\mathrm{ppm})\end{array}$ \\
\hline 0 & $16.44 \mathrm{a}$ & $305 \mathrm{c}$ & $25.67 \mathrm{c}$ & $8.45 \mathrm{a}$ & $389.65 \mathrm{a}$ & $24.21 \mathrm{~b}$ & $18.75 \mathrm{a}$ \\
400 & $14.67 \mathrm{a}$ & $2,149 \mathrm{~b}$ & $61.56 \mathrm{~b}$ & $2.90 \mathrm{~b}$ & $386.55 \mathrm{a}$ & $24.75 \mathrm{~b}$ & $18.11 \mathrm{a}$ \\
800 & $13.78 \mathrm{a}$ & $3,892 \mathrm{a}$ & $90.98 \mathrm{a}$ & $2.41 \mathrm{~b}$ & $381.28 \mathrm{~b}$ & $26.53 \mathrm{a}$ & $18.51 \mathrm{a}$ \\
\hline
\end{tabular}

Keterangan : Angka yang diikuti oleh huruf yang berbeda pada kolom yang sama adalah berbeda nyata pada uji DMRT taraf $5 \%$. HSAE = hari setelah aplikasi etepon 
Hasil penelitian ini menunjukkan bahwa tanaman durian dapat diinduksi pembungaannya melalui pemberian paklobutrazol dan etepon. Paklobutrazol berperanan dalam menekan sintesis giberelin, sehingga kandungannya menurun. Etepon berfungsi untuk memecah dormansi tunas generatif sehingga muncul kuncup bunga. Keberhasilan induksi pembungaan melalui penekanan giberelin oleh paklobutrazol sesuai dengan hasil penelitian terdahulu. Hasil penelitian Poerwanto et al. (1997) menunjukkan bahwa pemberian $0.25 \mathrm{~g}$ paklobutrazol per pohon pada bulan Desember dapat membungakan tanaman mangga mulai bulan Pebruari, sedangkan pemberian 2 g per pohon pada bulan yang sama dapat membungakan mangga mulai bulan Maret. Pemberian paklobutrazol pada bulan Januari dapat membungakan tanaman mangga pada bulan Maret, April, Mei; sedangkan pemberian pada bulan Pebruari dapat membungakan mangga pada bulan Juni atau Juli.

Pemberian paklobutrazol dapat menurunkan kandungan giberelin dan meningkatkan kandungan gula total dan $\mathrm{C} / \mathrm{N}$. Aplikasi paklobutrazol $2 \mathrm{~g}$ per pohon dan etepon 400 ppm menginduksi pembungaan manggis dan menghasilkan bobot buah manggis tertinggi $(25.5 \mathrm{~kg})$ atau lebih tinggi $321.49 \%$ dibandingkan dengan control (Rai et al., 2004)

Hasil penelitian Karaguzel et al. (2004) menunjukkan bahwa pemberian paklobutrazol pada Lupinus varius mempercepat munculnya bunga dan meningkatkan jumlah bunga yang terbentuk. Paklobutrazol merupakan suatu senyawa yang mempunyai aktivitas menekan giberelin pada periode transisi dari fase vegetatif ke generatif. Pengaruhnya terhadap pembungaan ditentukan oleh jenis tanaman (Cerny-Koenig et al., 2004).

\section{KESIMPULAN}

1. Pemberian paklobutrazol $4 \mathrm{~g}$ per pohon menunjukkan kandungan giberelin terendah dan kinetin tertinggi. Hal ini berkaitan dengan saat pertama berbunga yang lebih awal, jumlah bunga dan buah yang paling tinggi, namun fruit-set paling rendah.

2. Pemberian etepon 800 ppm per pohon menunjukkan kandungan giberelin terendah dan kinetin tertinggi. Perlakuan tersebut menghasilkan jumlah bunga dan jumlah buah tertinggi, namun fruit-set terendah dibandingkan konsentrasi etepon lainnya.
3. Kombinasi perlakuan 4 g paklobutrazol dan 800 ppm etepon per pohon menunjukkan kandungan geberelin dan asam absisat terendah dan menghasilkan jumlah bunga tertinggi.

\section{UCAPAN TERIMA KASIH}

Penulis mengucapkan terima kasih kepada Direktorat Penelitian dan Pengabdian pada Masyarakat Pendidikan Tinggi Kementerian Pendidikan Nasional atas pendanaan penelitian melalui Program Penelitian Strategis Nasional.

\section{DAFTAR PUSTAKA}

Baktir, I, S. Ulger, L. Kaynak, D.G. Hilmerick. 2004. Relationship of seasonal changes in endogenous plant hormones and alternate bearing of olive trees, HortScience 39(5):987-990.

Cerny-Koenig, T.A., J.E. Faust, N.C. Rajapakse. 2004. Role of gibberellins $\mathrm{A}_{4}$ and gibberellins biosynthesis inhibitors on flowering and stem elongation in Petunia under modified light environments. HortScience 40(1):134-137.

Karaguzel, O., I. Baktir, S. Cakmaci, V. Ortacesme. 2004. Growth and flowering responses of Lupinus varius L. to paclobutrazol. HortScience 39(7):16591663.

Naoko, K., B. Kenji, M. Sutasinee, B. Unaroj, S. Suranant, K. Ikuo. 2005. Development of reproductive organs and initial fruitset in peach and necatarine in the Norther Highlands of Thailand. Jap. J. of. Trop. Agric. 49(1):30-37.

Palese, A.M., S.J. Crocker. 2002. Preliminary investigations of endogenous gibberellins in seeds of olive fruits. ActaHort.586:525528.

Palupi, E.R, J.N. Owens, S. Sadjad, Sudarsono, D.D. Solihin. 2010. The omportance of fruit set, fruit abortion, and pollination success in fruit production of teak (Tectona grandis). Can. J. For.Res.40:2204-2214. 
Poerwanto, R., D. Efendi, S.S. Harjadi. 1997. Pengaturan pembungaan mangga Gadung 21 di luar musim dengan paklobutrazol dan zat pemecah dormansi. Hayati 4(2)41-46.

Poerwanto, R. 2003. Peran manajemen budidaya tanaman dalam peningkatan ketersediaan dan mutu buah-buahan. Orasi ilmiah sebagai guru besar tetap Ilmu Hortikultura Fakultas Pertanian Institut Pertanian Bogor, Bogor 13 September 2003.
Rai, I.N., R. Poerwanto, L.K. Darusman, B.S. Purwoko. 2004. Pengaturan pembungaan tanaman manggis (Garcinia mangostana L.) di luar musim dengan strangulasi, serta aplikasi paklobutrazol dan etepon. Bul.Agron.(32)(2)12-20. 